\title{
Website Based E-Commerce Waste Recycling Products
}

\section{E-Commerce Produk Daur Ulang Sampah Berbasis Website}

\author{
Setyorini $^{1 *}$, Syarif Hidayatullah ${ }^{2}$, Ike Kusdyah Rachmawati \\ \{setyorini@asia.ac.id ${ }^{1}$, syarif.hidayatullah@unmer.ac.id², ikekusdyah@gmail.com³ ${ }^{3}$,
}

Institut Teknologi dan Bisnis Asia Malang, Jl.Soekarno Hatta- Rembuksari 1A, Malang1,3, Universitas Merdeka Malang, Jalan Terusan Dieng No. 62-64 Klojen, Pisang Candi, Kec. Sukun, Kota Malang²

\begin{abstract}
The use of websites and social media as sales engines has begun to develop in line with the advancement of e-commerce. The waste bank is a waste material resource that can be recycled and made into a usable product whose existence has been ongoing until now but does not yet have an online promotional media that suits your needs. Creating a website that is in accordance with the intended flow of needs so that the website can make it easier for waste bank managers to widely market recycled products and reach consumers nationally. Especially at the Garbage Bank Recycling Product Gallery, Mojo Sari village, Malang Regency. The waste bank recycling e-commerce website created will be able to solve customer service problems that have been complained of. The impact is the increased level of customer satisfaction with ease of viewing product information, ease of ordering, and payment processing.
\end{abstract}

Keywords - e-commerce; website; waste bank

\begin{abstract}
Abstrak. Memanfaatkan website dan sosial media sebagai mesin penjualan sudah berkembang sejalan dengan perkembangan e-commerce. Bank sampah merupakan sumber daya bahan sampah-sampah yang dapat didaur ulang dan dijadikan produk yang dapat digunakan kembali keberadaannya hingga saat ini telah berlangsung namun belum memiliki media promosi secara online yang sesuai dengan kebutuhan masyarakat. Pembuatan dan pemanfaat website yang sesuai dengan alur kebutuhan yang dimaksud agar website dapat memberikan kemudahan bagi pengelola bank sampah dalam memasarkan dan memperkenalkan secara luas produk hasil daur ulang dan dapat menjangkau konsumen secara nasional dan internasional. Khusus nya di Galeri Produk Daur Ulang Bank Sampah Desa Mojo Sari Kabupaten Malang. Website e-commerce daur ulang bank sampah yang dibuat akan dapat mengatasi dan membantu permasalahan layanan pelanggan yang selama ini sering dikeluhkan. Dampaknya adalah meningkatnya tingkat kepuasan masyarakat sebagai pelanggan terhadap kemudahan dalam melihat informasi produk hasil pengolahan limbah sampah, kemudahan melakukan pemesanan, hingga proses pembayaran produk daur ulang bank sampah.
\end{abstract}

Kata Kunci - e-commerce; website; bank sampah

\section{Pendahuluan}

Daur ulang adalah proses untuk menjadikan suatu bahan bekas menjadi bahan baru dengan tujuan mencegah adanya sampah yang sebenarnya dapat menjadi sesuatu yang berguna, mengurangi penggunaan bahan baku yang baru, mengurangi penggunaan energi, mengurangi polusi, kerusakan lahan, dan emisi gas rumah kaca jika dibandingkan dengan proses pembuatan barang baru [1]. Daur ulang adalah salah satu strategi pengelolaan sampah padat yang terdiri atas kegiatan pemilahan, pengumpulan, pemprosesan, pendistribusian dan pembuatan produk/material bekas pakai, dan komponen utama dalam manajemen sampah modern dan bagian ketiga dalam proses hierarki sampah 4R (Reduce, Reuse, Recycle, and Replace) [2].

Material yang bisa didaur ulang terdiri dari sampah kaca, plastik, kertas, logam, tekstil, dan barang elektronik. Meskipun mirip, proses pembuatan kompos yang umumnya menggunakan sampah biomassa yang bisa didegradasi oleh alam, tidak dikategorikan sebagai proses daur ulang. Daur ulang lebih difokuskan kepada sampah yang tidak bisa didegradasi oleh alam secara alami demi pengurangan kerusakan lahan. Secara garis besar, daur ulang adalah proses pengumpulan sampah, penyortiran, pembersihan, dan pemprosesan material baru untuk proses produksi.

Pada pemahaman yang terbatas, proses daur ulang harus menghasilkan barang yang mirip dengan barang aslinya dengan material yang sama, contohnya kertas bekas harus menjadi kertas dengan kualitas yang sama, atau busa polistirena bekas harus menjadi polistirena dengan kualitas yang sama. Seringkali, hal ini sulit dilakukan karena lebih mahal dibandingkan dengan proses pembuatan dengan bahan yang baru. Jadi, daur ulang adalah proses penggunaan kembali material menjadi produk yang berbeda. Bentuk lain dari daur ulang adalah ekstraksi material berharga dari sampah, seperti emas dari prosesor komputer, timah hitam dari baterai, atau ekstraksi material yang berbahaya bagi lingkungan, seperti merkuri. Daur ulang adalah sesuatu yang luar biasa yang bisa didapatkan dari sampah. Proses daur ulang aluminium dapat menghemat $95 \%$ energi dan mengurangi polusi udara sebanyak $95 \%$ jika dibandingkan dengan ekstraksi aluminium dari tambang hingga prosesnya di pabrik. Penghematan yang cukup besar pada energi juga didapat dengan mendaur ulang kertas, logam, kaca, dan plastik. 
Seperti yang terjadi pada Desa Mojosari awalnya merupakan desa tertinggal dengan tingkat kebersihan yang sangat rendah, namun dengan adanya manajemen Bank Sampah yang baik Desa Mojosari mampu memajukan desanya hingga diakui di Kabupaten Malang [3]. Namun sayangnya manajemen bank sampah tersebut tidak dibarengi dengan manajemen pemasaran yang baik, Desa mojosari hanya menggunakan media toko atau galeri sebagai media pemasarannya. Sehingga dengan adanya penelitian ini, penulis ingin memberikan solusi pemanfaat teknologi sebagai media pemasaran produk olahan sampah yang dihasilkan dalam bentuk e-commerce [4].

Pemanfaatan website dan sosial media sebagai mesin penjual sudah mulai berkembang sejalan dengan kemajuan e-commerce. Bank sampah merupakan sumber daya bahan sampah yang dapat didaur ulang dan dijadikan produk layak pakai yang keberadaannya hingga saat ini telah berlangsung namun belum memiliki media promosi online yang sesuai dengan kebutuhan. Pembuatan website yang sesuai dengan alur kebutuhan dimaksud agar website bisa memberikan kemudahan bagi pengelola bank sampah dalam memasarkan secara luas produk hasil daur ulang dan dapat menjangkau konsumen secara nasional [5]. Website ini hanya kumpulan file yang terletak pada komputer yang terhubung ke internet [6]. Konsep inti dari penerapan model e-commerce ini meliputi: kebutuhan, permintaan, informasi produksi, utilitas, pertukaran, konsumen dan transaksi penjual.

\section{METODE}

\section{A. Metodelogi pengumpulan data} [7] :

Data pada penelitian ini metode pengumpulan data dengan menggunakan beberapa metode diantaranya adalah

\section{Studi kepustakaan}

Studi kepustakaan dilakukan dengan mencari sumber pustaka yang mendukung penelitian serta akan memberikan informasi yang sesuai dalam menyelesaikan penelitian ini. Sumber studi kepustakaan yang digunakan antara lain adalah berasal dari buku, jurnal, artikel dan paper.

Observasi

Observasi dilakukan dengan cara pengamatan langsung terhadap objek yang akan diteliti berkaitan dengan permasalahan yang akan dibahas, yaitu dengan mengunjungi gallery bank sampah untuk melihat dan mengamati kegiatan yang terjadi antara pengelola bank sampah dengan pelanggan.

\section{B. Metode pengembangan software}

Analisis kebutuhan software

Analisis kebutuhan perangkat lunak dilakukan untuk menggali kebutuhan software yang akan dibangun. Hasil dokumen analisis kebutuhan software ini berupa sebuah dokumen Spesifikasi KebutuhAn Perangkat Lunak (SKPL) [8].

Perancangan software

Perancangan software dilakukan untuk merancang software yang akan dibangun sehingga dapat diperoleh gambaran detail sistem. Hasil dari perancangan software ini berupa sebuah dokumen Deskripi Perancangan Perangkat Lunak (DPPL).

\section{Implementasi software}

Implementasi software dilakukan dengan membuat aplikasi sistem informasi untuk membantu memberikan informasi promo, produk, serta informasi kegitan Gallery Bank Sampah [9].

\section{Pengujian software}

Pengujian pengujian software yang dilakukan yaitu pengujian fungsionalitas software yang dilakukan oleh pengembang perangkat lunak. Hasil dari pengujian software ini berupa sebuah dokumen Perencanaan, Deskripsi dan Hasil Uji Perangkat Lunak (PDHUPL) [10].

\section{Pengujian hasil software oleh responden}

Pengujian software oleh responden dilakukan dengan cara membagikan kuisioner kepada responden. Kuisioner digunakan untuk mendapatkan data pengujian perangkat lunak yang meliputi uji fungsionalitas software dan uji konten software. Sasaran responden yang digunakan dalam pengujian adalah masyarakat yang menggunakan jasa Pemasaran Produk Olahan Sampah Kuisioner dilakukan secara online terhadap masyarakat yang dimaksud.

\section{HASIL DAN PEMBAHASAN}


Cara kerja [11]Payment pada e-commerce Galeri Daur Ulang Bank Sampah Desa Mojosari Kepanjen Kabupaten Malang.

1. Customer adalah pengunjung website e-commerce Galeri Daur Ulang Bank Sampah. Setelah customer menemukan pemilihan barang yang cocok, Customer memutuskan untuk membelinya. Selanjutnya, customer memasukkan informasi yang diperlukan, termasuk informasi kartu kredit atau debit yang akan digunakan untuk membayar.

2. Detail transaksi customer diteruskan kepada payment gateway informasi pribadi dan kartu kredit yang customer masukkan sebelumnya dikirimkan ke payment gateway yang memiliki dan berfungsi sebagai perantara antara informasi dari pelanggan dan bank [12]. Detail transaksi tersebut diproses secara aman oleh payment gateway untuk selanjutnya dikirimkan ke payment processor, lalu diteruskan ke akun admin Galeri Daur Ulang Bank Sampah Desa Mojosari berdasarkan nomor ID pedagang serta detail transaksi.

3. Payment processor akan menghubungi bank. Selain mengirimkan rincian transaksi kepada akun pedagang, payment processor juga memiliki tugas untuk menghubungi bank penerbit kartu kredit atau debit (issuing bank) yang digunakan oleh Customer. Hal ini bertujuan untuk mengetahui apakah kartu yang digunakan oleh Customer sudah melewati batas transaksi. Selain itu, hal ini juga akan dilakukan untuk memastikan kartu yang digunakan oleh Customer adalah kartu yang sah atau benar [13]. Proses ini biasanya terjadi dalam jaringan khusus yang menghubungkan antara payment processor dan bank, sehingga proses ini akan berlangsung dalam waktu yang relatif instan.

4. Konfirmasi dari bank. Bank akan memberikan tanggapan berupa persetujuan atau penolakan berkaitan dengant detail transaksi yang sudah dilakukan. Informasi ini akan dikirimkan oleh bank kepada payment processor melalui jalur khusus yang sebelumnya sudah digunakan.

5. Payment Processor mengirim hasilnya ke payment gateway [14]. Jika hasil disetujui, payment processor menyampaikan informasi tersebut ke payment gateway, yang kemudian akan disimpan sebagai bukti agar website e-commerce dapat memproses pembelian yang dilakukan oleh Customer .

6. Memulai Pengiriman Produk. Galery bank sampah akan menerima informasi bahwa transaksi berhasil dilakukan. Selanjutnya gallery bak sampah harus mulai mempersiapkan pengiriman produk tersebut ke alamat Customer.

7. Produk Daur Ulang Bank Sampah akan di bayar. Bank yang mengeluarkan kartu Customer akan mengirimkan dana ke bank yang Anda gunakan. Setelah proses itu dilakukan, Admin hanya perlu menunggu dana yang dikirimkan masuk kedalam rekening Galeri Daur Ulang Bank Sampah.

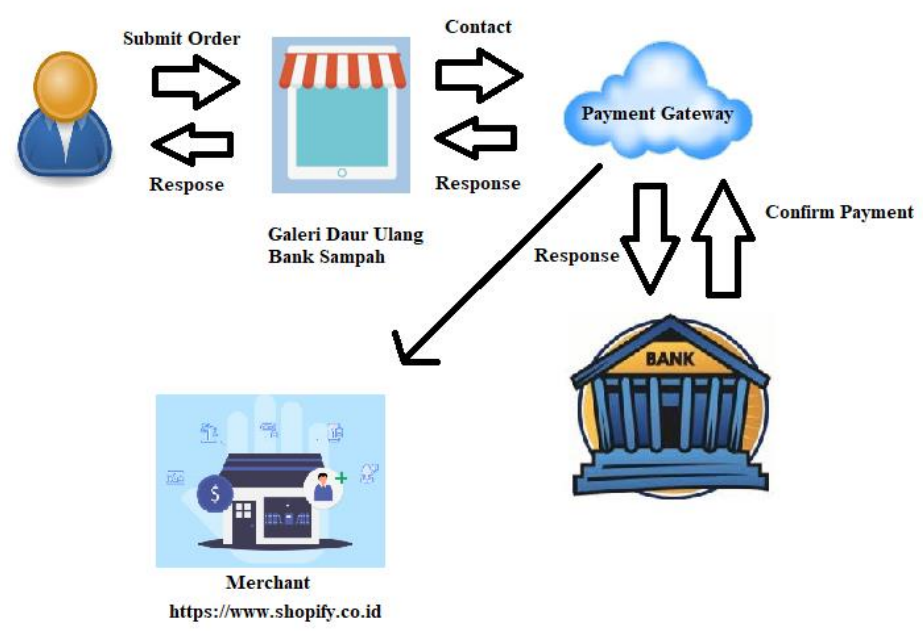

Gambar 1. Cara kerja Payment pada e-commerce Galeri Daur Ulang Bank Sampah 
Procedia of Engineering and Life Science Vol. 1. No. 2 Juni 2021

Seminar Nasional \& Call Paper Fakultas Sains dan Teknologi (SENASAINS 2nd)

Universitas Muhammadiyah Sidoarjo
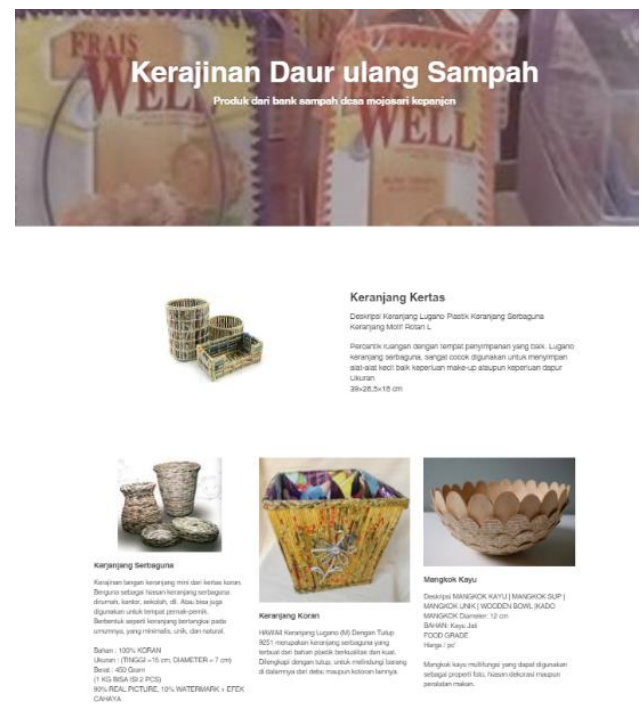

Gambar 2. Home Page
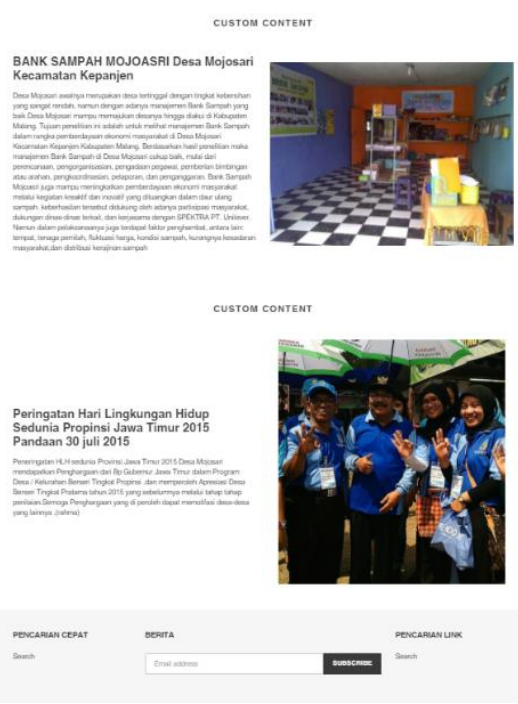

Gambar 3. Kegiatan Galeri Bank Sampah

Halaman kegiatan galeri pengolahan daur ulang bank sampah

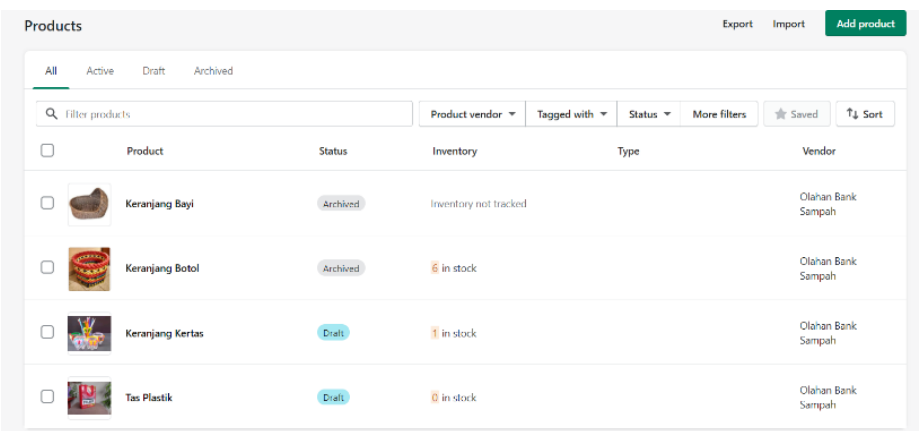

Gambar 4. Produk yang dijual 


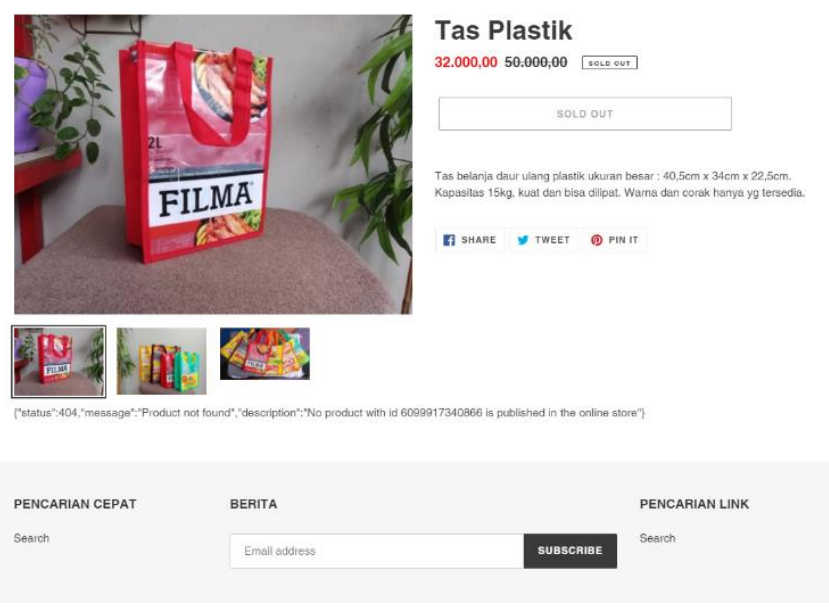

Gambar 5. Detail Produk

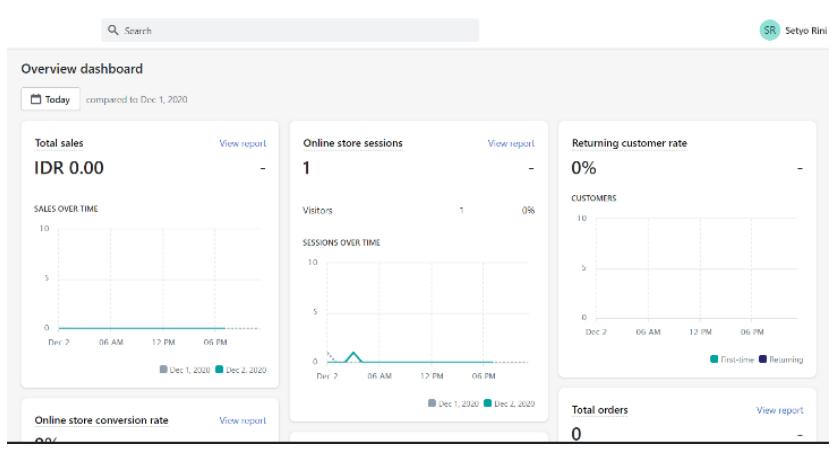

Gambar 6. Overview Dashboard

\section{KESIMPULAN}

Website e-commerce daur ulang bank sampah yang dibuat akan dapat mengatasi permasalahan layanan pelanggan yang selama ini dikeluhkan. Dampaknya adalah meningkatnya tingkat kepuasan pelanggan terhadap kemudahan dalam melihat informasi produk, kemudahan pemesanan, hingga proses pembayaran.

\section{REFERENSI}

[1] D. Kobar, "DLH Sosialisasikan Sampah dan Daur Ulang Kepada Anggota Pramuka Di Gudep SMAN 1 Kumai," 2019.

[2] U.-u. R. I. n. 18, “pengelolaan sampah,” 20078.

[3] \&.P. I. F. Ismawan, "Prototipe Knowledge Management System Berbasis E-Business : Studi Kasus Margatekno Official Center,” 2015, p. 231-241.

[4] H. Sukoco, "Pengantar Database Management System.W.-K. Chen, Linear Networks and Systems," 2005, p. 123-135.

[5] G. Gunadi, "Pengembangan Aplikasi Web Berbasis Flexbox Untuk Pengelolaan Jadwal Produksi Dan Dokumen Digital Menggunakan Framework Bulma DI PT. GRAMEDIA," INFOTECH," Journal of Technology Information, vol. 4, pp. 42-47, 2019.

[6] J. Sarwono, "Teori e-commerce kunci sukses perdagangan di internet," Yogyakarta, Gava media, 2008.

[7] S. Nasution, Metode research, penelitian ilmiah, Jakarta: Penerbit Bumi Aksara, 2009. 
[8] M. Nazir, "Metode Penelitian," dalam Ghalia IndonesiaB. Smith, "An approach to graphs of linear forms (Unpublished work style), Jakarta, unpublished, 1988.

[9] A. S. \&. S. Santoso, "Analisa dan Perancangan Sistem Informasi Penjualan Online (ECommerce) pada CV Selaras Batik Menggunakan Analisis Deskriptif," p. 53-64, 2014.

[10] ,. A. L. d. S. A. O.W. Purbo, "Alternatif pengembangan jaringan komputer biaya murah: sebuah studi kasus".

[11] F. Isnanto, "Memaksimalkan fungsi ecommerce menggunakan sistem payment gateway, STMIK Atma Luhur Pangkal Pinang," 2013.

[12] S.Karyana, "Manfaat Sistem Informasi Manajemen Sebagai Sarana Sosialisasi Pasar Tradisional Secara Online Kepada Masyarakat," Universitas Muhammadiyah Metro, 2014.

[13] R. E. H. a. C. T. Case, "Transient signal propagation in lossless isotropic plasmas," USAF Cambridge Res. Lab., Cambridge, MA Rep, 1994.

[14] P. N. P. R. S. A. S. P. \&. S. M. R. Andita, "Analisis dan Perancangan Sistem Informasi Pelayanan Obat di Apotek Generik. Jurnal Edukasi Dan Penelitian Informatika (JEPIN)," 2016. 